\title{
Combination Cell Therapy with Mesenchymal Stem Cells and Neural Stem Cells for Brain Stroke in Rats
}

\author{
Seyed Mojtaba Hosseini ${ }^{1,2,3}$, Mohammad Farahmandnia, ${ }^{1,2}$, Zahra Razi ${ }^{1,2}$, Somayeh Delavari, ${ }^{1,2}$, \\ Benafsheh Shakibajahromi ${ }^{1,2}$, Fatemeh Sabet Sarvestani ${ }^{1,2}$, Sepehr Kazemi ${ }^{1,2}$, Maryam Semsar ${ }^{1,2}$ \\ ${ }^{1}$ Student Research Committee, Shiraz University of Medical Sciences, Shiraz, Iran \\ ${ }^{2}$ Cell and Molecular Student Research Group, Medical School, Shiraz University of Medical Sciences, Shiraz, Iran \\ ${ }^{3}$ Stem Cell laboratory, Department of Anatomy, Shiraz University of Medical Sciences, Shiraz, Iran
}

\begin{abstract}
Objectives: Brain stroke is the second most important events that lead to disability and morbidity these days. Although, stroke is important, there is no treatment for curing this problem. Nowadays, cell therapy has opened a new window for treating central nervous system disease. In some previous studies the Mesenchymal stem cells and neural stem cells. In this study, we have designed an experiment to assess the combination cell therapy (Mesenchymal and Neural stem cells) effects on brain stroke.

Method and Materials: The Mesenchymal stem cells were isolated from adult rat bone marrow and the neural stem cells were isolated from ganglion eminence of rat embryo 14 days. The Mesenchymal stem cells were injected 1 day after middle cerebral artery occlusion (MCAO) and the neural stem cells transplanted 7 day after MCAO. After 28 days, the neurological outcomes and brain lesion volumes were evaluated. Also, the activity of Caspase 3 was assessed in different groups.

Result: The group which received combination cell therapy had better neurological examination and less brain lesion. Also the combination cell therapy group had the least Caspase 3 activity among the groups.

Conclusions: The combination cell therapy is more effective than Mesenchymal stem cell therapy and neural stem cell therapy separately in treating the brain stroke in rats.
\end{abstract}

Keywords: Mesenchymal stem cells, Neural stem cells, Combination cell therapy, Brain stroke

\section{Introduction}

Stroke leads to $9 \%$ of death in adults worldwide, and it is the most important death cause after ischemic heart disease (1). Considering some proven benefit interventions

\footnotetext{
Accepted for publication February 8, 2015, Published online May 30, 2015 Correspondence to Seyed Mojtaba Hosseini

Student Research Committee, Shiraz University of Medical Sciences, Zand Blvd, Shiraz, Iran

Tel: +98-71-32122970, Fax: +98-71-32122970

E-mail: hoseini2010m@gmail.com

(c) This is an open-access article distributed under the terms of the Creative Commons Attribution Non-Commercial License (http://creativecommons.org/ licenses/by-nc/4.0/), which permits unrestricted non-commercial use, distribution, and reproduction in any medium, provided the original work is properly cited.
}

such as aspirin and tissue plasminogen activator, there is no definite treatment for brain stroke (2). Stroke caused disability has been mentioned the sixth common cause for reducing disability adjusted life years (3). Actually, a small amount of the patient with stroke could recover fully and the majority of them have to have some life-long neurological deficits such as paralysis, memory difficulties, thinking and language problems (4-6). The most common cause of stroke is the sudden onset occlusion of the brain arteries by an embolism or a thrombosis, so the blood flow would decrease and oxygen and glucose shortage could occur and as a result different pathology for neurological impairment could be started (7). The cerebral ischemia pulls the trigger of two major pathophysiologies cause in brain stroke, fist it provides the inflammation 
and second oxidative stress; and both of them can cause the neuronal apoptosis and secondary consequences of the cerebral ischemia (8).

Stem cell based therapy is a new approach in neurodegenerative diseases on central nervous system (CNS) which is potent to solve major pathophysiologies due to the stem cells ability in reducing the inflammation, reconstructioning of blood brain barrier and making some neural regenerations by secreting some neurotrophic factors including basic fibroblast growth factor (bFGF), endothelial growth factor (EGF), brain derived neurotrophic factor (BDNF), vascular endothelial growth factor (VEGF), etc. (9-11).

In this study, for treating brain stroke, firstly Mesenchymal stem cells were transplanted in acute phase after stroke ( 1 day), they might diminish the inflammation and provide an appropriate microenvironment for regeneration after ischemia. Second the neural stem cells were transplanted in sub acute phase (7 days) after ischemia for promoting regeneration due to their capability to differentiate into three neural lineage cells (neurons, oligodendrocytes and astrocytes) with the support of Mesenchymal stem cells in making the microenvironment suitable for neural regeneration.

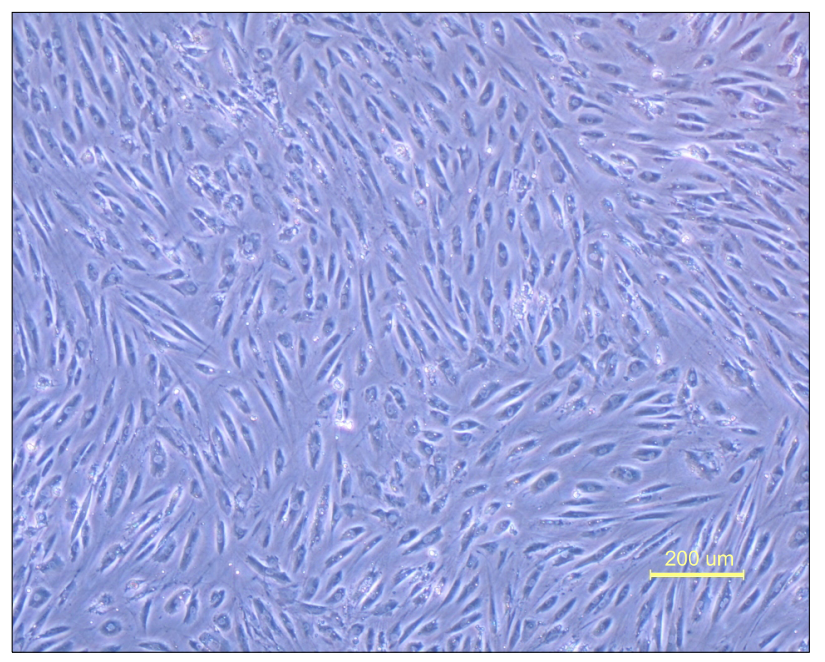

Fig. 1. Rat bone marrow mesenchymal stem cells.

\section{Materials and Methods}

All animals were obtained from the Laboratory Animal House of Shiraz University of Medical Sciences (SUMS) and kept in standard condition under 12-hour light/dark cycle, and were fed food and water ad libitum. All procedures in this study were conducted based on the guidelines of the Ethical Committee of SUMS. This research was approved and granted by SUMS.

\section{Bone Marrow Mesenchymal stem cells isolation and expansion}

For isolating the bone marrow Mesenchymal stem cells (MSC) a 250 300 g rat was selected from animal laboratory, the rat was killed by cervical dislocation according to Shiraz University of Medical Sciences ethical guideline.

The femur and tibia were isolated and flashed with complete culture media (DMEM containing 10\% fetal bovine serum and $1 \%$ pen/strep) the isolated cells were centrifuged at $800 \mathrm{~g}$ for 15 minutes, then cultured in complete culture media in $37^{\circ} \mathrm{C}$ and $5 \% \quad \mathrm{CO}_{2}$, the media was changed after 2 days (12). The culture flask was $80 \%$ confluent after 7 days and they were passaged by adding tryp$\sin 0.05 \%$ (Gibco), the cells were passaged 1:2 (Fig. 1).

\section{Bone marrow Mesenchymal stem cells characterization}

The expression of Mesenchymal stem cells markers (CD34, CD44, CD90 and CD45) were assessed by immunocytochemistry method. Briefly, the cells were fixed with paraformaldehyde $4 \%$ for 20 minutes in $+4^{\circ} \mathrm{C}$, then the primary antibody diluted in phosphate buffer saline (PBS) including 5\% goat serum and kept for 1 hour in room temperature. After washing three times with PBS, the secondary antibodies were diluted in PBS and 5\% goat serum was added and after 1 hour keeping the cells in room temperature, the cells washed again with PBS (Table 1) (13).

\section{Neural stem cells Isolation}

The ganglion eminences were dissected from embryo 14 days of Sprague-Dawley rats, the gathered tissue were transferred in neural stem cell culture media (DMEM/F12, $2 \%$ B27, $1 \%$ N2, bFGF $10 \mu \mathrm{g} / \mathrm{ml}$ and EGF $20 \mu \mathrm{g} / \mathrm{ml}$ ) and they were pipette for reaching single cells. One week

Table 1. Rat bone marrow Mesenchymal stem cells markers expression

\begin{tabular}{ccccc}
\hline & CD90 & CD44 & CD45 & CD34 \\
\hline Bone Marrow Mesenchymal stem cell & $94.08 \% \pm 1.28$ & $91.15 \% \pm 0.78$ & $2.11 \% \pm 0.71$ & $2.70 \% \pm 0.39$ \\
\hline
\end{tabular}




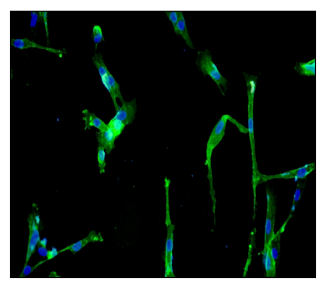

CD44

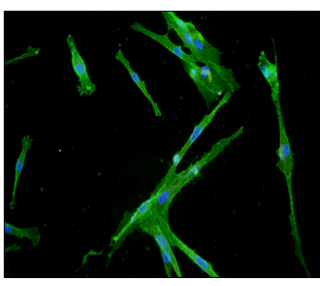

CD90

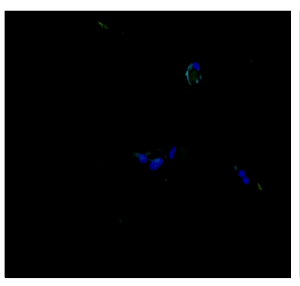

CD34

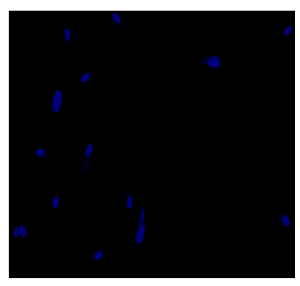

CD45
Fig. 2. Immunocytochemistry for CD44, CD45, CD90 and CD34.

later some spheres formed in culture flask called neurospheres (Fig. 2) (14).

\section{Neural stem cells characterization}

Passage 3 neural stem cells were singled by using tryp$\sin 0.05 \%$ and cultured on poly-ornithin coated plates. For differentiating to three neural lineages, fetal bovine serum $5 \%$ was added to the neural stem cells culture media after removing bFGF and EGF. Three days later, the neural stem cells were differentiated to neurons, oligodendrocytes and astrocytes. To confirm the differentiation of the NSCs, immunocytochemistry was performed for $\beta$-tubulinIII (neuron marker) and GFAP (astrocyte marker) (13). The immunocytochemistry was done as mentioned before (Fig. 3).

\section{Animal Preparation}

All procedures approved by ethical committee of Shiraz University of Medical Sciences. Male Sprague-Dawley rats (200 250 g) were selected randomly and they had free access to food and water. They divided to 5 groups and each group had $10(n=10)$ rats. First group that received no intervention and treatment called control group, second group which has been induced middle cerebral artery occlusion (MCAO) and received $20 \lambda$ PBS intraventrically called sham group, third one which underwent MCAO operation received 100000 Mesenchymal stem cell diluted in $20 \lambda$ PBS one day after stroke intraventrically, forth group that underwent MCAO operation received 100000 neural stem cell diluted in $20 \lambda$ PBS seven day after stroke intraventrically and the last group which received combination cell therapy that means 100000 Mesenchymal stem cells transplantation after 1 day and 100000 neural stem cells transplantation after 7 days intraventrically.

\section{Middle Cerebral Occlusion Artery Inducing}

Anesthesia was performed by halothane (5\% induction and $2 \%$ maintenance) in a mixture of $\mathrm{NO}_{2}$ and $\mathrm{O}_{2}(50: 50)$. According to Koizumi's method Middle Cerebral Artery Occlusion (MCAO) was induced. Briefly, a vertical incision was excised in the midline of the rat's neck and the muscles, submandibular salivary gland was dissected

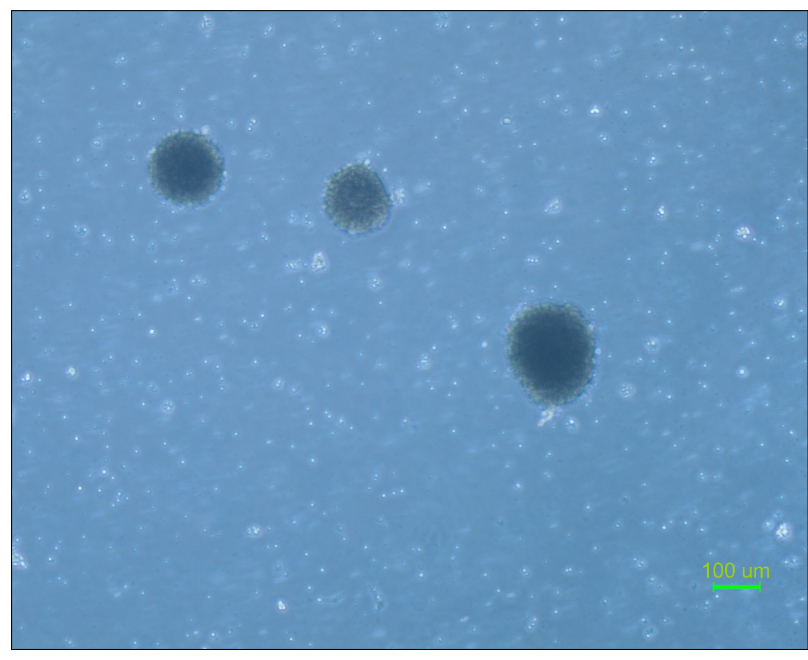

Fig. 3. Neurospheres.

and the carotid sheath was removed and the vagus nerve was separated from common carotid artery. Two loose sutures were prepared around common carotid and external carotid artery was clamped $3 \mathrm{~mm}$ before carotid bifurcation. The sutures were tightened and the blood flow was stopped, then a little incision was performed after sutures and before bifurcations and a silicon coated 4.0 nylon suture with round tip was inserted in common carotid artery till a mild resistance felled. For reperfusion blood flow after 60 , the 4.0 nylon suture was removed and the common carotid artery sutures were tightened completely (15).

\section{Neurological function assessment}

Neurological examinations were performed every two days for all rats during 28 days of experiment. The neurological examination was scored on six-score scale. The scores are following as below (16):

Score of 0: No neurological deficit

Score of 1: Failure to extend left forepaw completely. It shows mild focal neurological deficit

Score of 2: Circling to the left. It means a moderate focal neurological deficit

Score of 3: Falling to the left. It indicates a sever focal 
neurological deficit

Score of 4: Not walking spontaneously and decreasing level of consciousness.

Score of 5: Death due to brain ischemia

\section{Stereotactic Injection of Mesenchymal Stem Cells and Neural stem cells}

The animals were anesthetized with Isofluoran (induction $5 \%$ and maintenance $1 \%$ ) and then fixed to the stereotactical Frame, the neural stem cells and mesenchymal stem cells were injected into right lateral ventricle at: Anterioposterior $(\mathrm{AP})=-0.12 \mathrm{~mm}$, mediolateral $(\mathrm{ML})=1.6 \mathrm{~mm}$, dorsoventricular (DV) $=4.3 \mathrm{~mm}$.

\section{Histology}

After 28 days, the rats were anesthetized with Halothane and were fixed with normal saline followed Paraformaldehyde $4 \%$, cry sections $(10 \mu \mathrm{m})$ were mounted on silicon coated slides and stained with Hematoxin \& Eosin.

\section{Apoptosis evaluation with measurement of Caspase 3 activity}

Activation of ICE family proteases/caspases initiates apoptosis in mammalian cells. This assay is based on spectrophtorometric detection of chromophore p-nitroaniline ( $p$-NA) after cleavage from labeled substrate DEVD- $p$-NA. The $p$-NA light emission could be measured by using spectrophotometer at $400 \sim 405 \mathrm{~nm}$. For this assay Caspase 3 assay kit from Abcam Company was used (ab39401).

\section{Statistical Analysis}

Data were statistically analyzed using SPSS 11.0 statistical software and expressed as the mean $\pm \mathrm{SD}$. Differences between groups were compared using one way-ANOVA test. Statistical significance was set at $\mathrm{p}<0.05$.

\section{Results}

\section{Bone marrow Mesenchymal stem cells}

After 7 days culturing Mesenchymal stem cells, the tissue flask confluent about $80 \%$ with stem cells which are characterized morphologically by long and thin cell process and a small cell body. The isolated Mesenchymal stem cells were positive for CD44 and CD90 and they were negative for CD34 and CD45 (Fig. 1, 2, Table 1).

\section{Neural stem cells expansion and differentiation}

Five days after culturing the isolated cells from ganglion eminence some spheres has been formed by neural stem cells called neurospheres. Each neurospheres was dissociated and the cells expressed Nestin $(70.02 \% \pm 8.10)$. The neural stem cells were differentiated to neuron, oligodendrocyte and astrocyte by adding $5 \%$ fetal bovine serum after 2 days (Fig. 3).

The neuron differentiation and astrocyte differentiation were evaluated by immunocytochemistry staining with $\beta$ tubulin III and GFAP antibodies (Fig. 4, Table 2).

\section{Neurological scores}

The neurological outcomes were assessed as previously described according to the scale scoring. The group which received combination cell therapy had the best neurological performance which means that the combination cell therapy could be the most effective treatment for brain stroke in comparison with Mesenchymal stem cells

Table 2. The table for percentage of neurons and astrocytes

$\beta$-tubulin III GFAP

Neural stem cells differentiation $12.73 \% \pm 2.60 \quad 80.53 \% \pm 3.53$

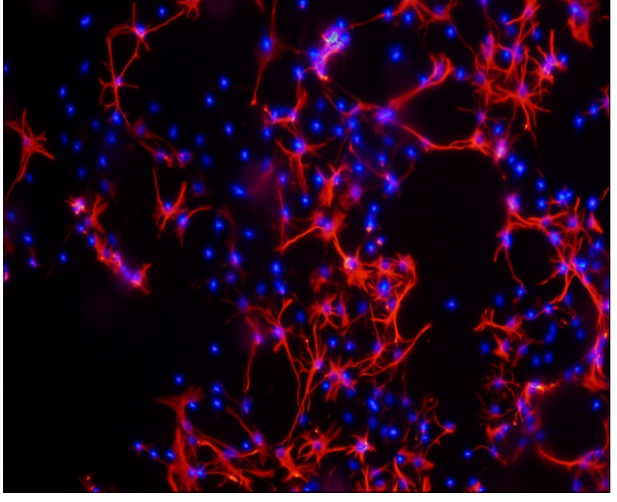

$\beta$-tubulin III

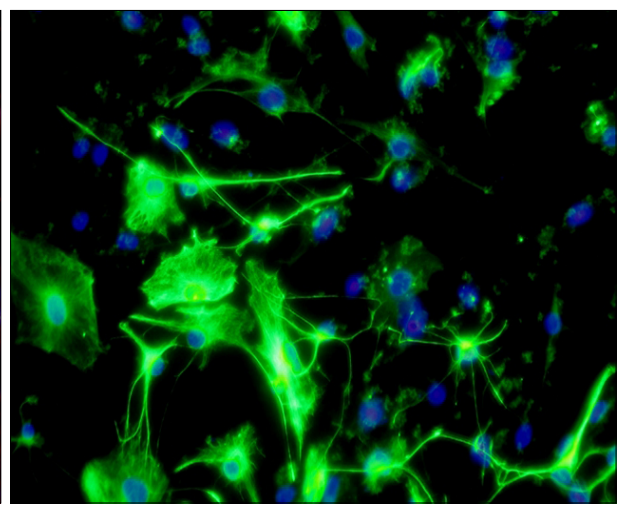

GFAP
Fig. 4. Immunocytochemistry for $\beta$ tubulin and GFAP. 


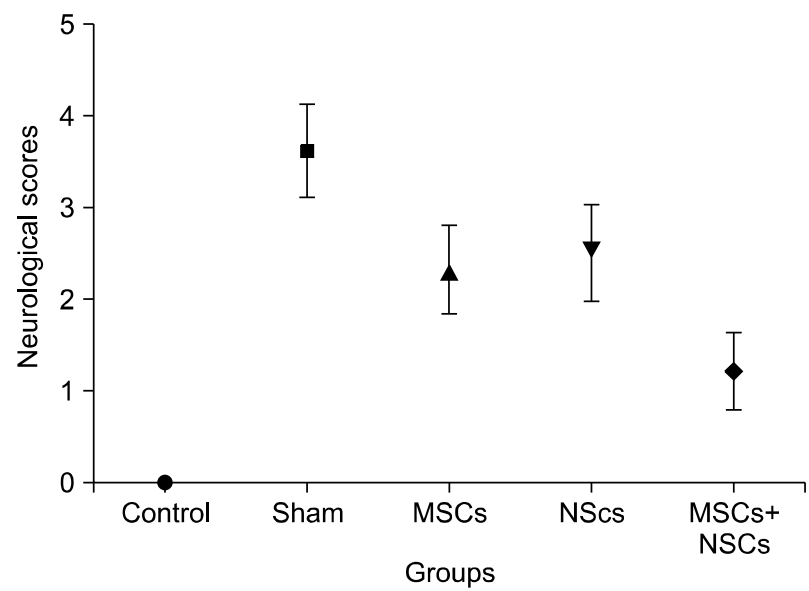

Fig. 5. Neurological function assessment.

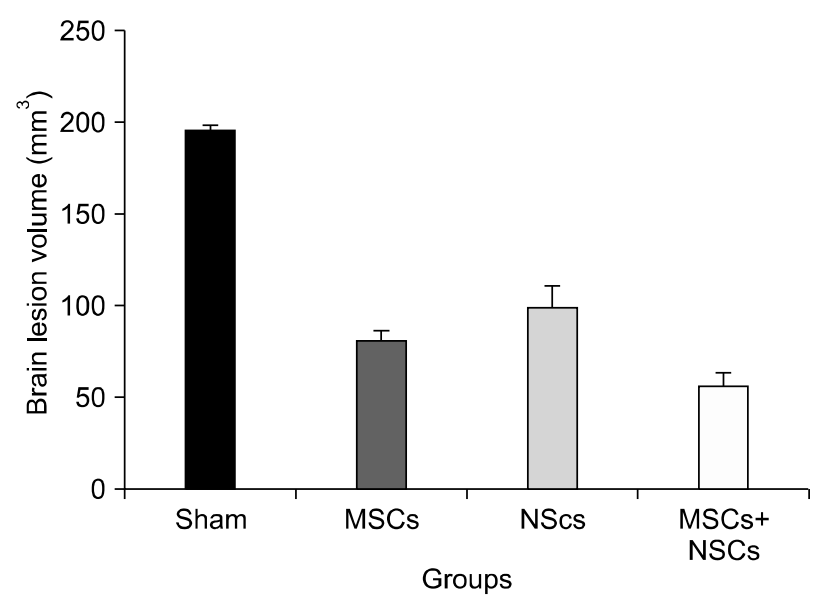

Fig. 6. Histology study.

and neural stem cells treated groups (Fig. 5).

\section{Histology Study}

The coronal sections were selected with $1 \mathrm{~mm}$ interval and from the first one was $2 \mathrm{~mm}$ posterior to frontal pole. Damaged area was determined by some ischemic signs including eosinophilic cytoplasm and pyknotic nuclei. The lesion volume in group that received combination cell therapy is the least one among the other groups (56.26 $\mathrm{mm}^{3} \pm 7.69$ ) and there was a significant difference ( $\mathrm{p}$ value $<0.05$ ) (Fig. 6).

\section{Caspse3 Activity Assay}

Some stem cells are capable of reducing apoptosis by down regulating some apoptotic genes such as caspase 3 (17). Caspase 3 activity was evaluated by spectrophotometer at $405 \mathrm{~nm}$. The higher absorbance value indicated the higher Caspase 3activity and as a result the higher in-

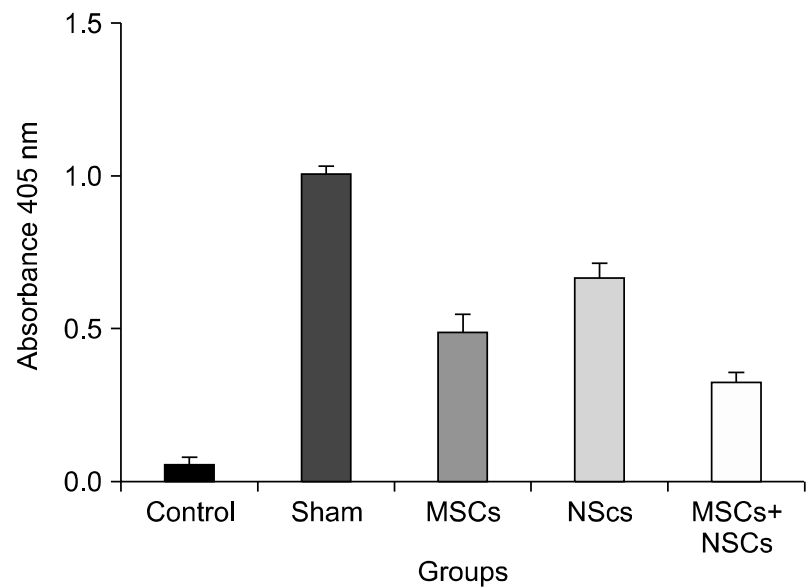

Fig. 7. Caspase 3 Activity Assay.

cidence of apoptosis. The result illustrates that the combination cell therapy group had the least amount of Caspase 3 activity between the rests of the groups and as a result the lowest amount of apoptosis (0.32 \pm 0.04$)$ (Fig. 7).

There was a significant difference between the groups ( $\mathrm{p}$ value less than 0.05 )

\section{Discussion}

Present study revealed that the combination cell therapy with Mesenchymal stem cells and neural stem cells could improve neurologic function after brain stroke. One the other hand the transplantation of Mesenchymal stem cells and neural stem cells separately could make better neurological outcome but they are less than combination cell therapy.

Mesenchymal stem cell could be beneficial for brain stroke recovering in different aspects. Cheng et al. in 2015 have demonstrated that Mesenchymal stem cells could attenuated inflammatory cytokines such as TNF- $\alpha$, IL -17, IL-23, etc and promote the expression of TGF- $\beta$ which is result in modulating the inflammation (18). Also related to anti-inflammatory character of MSCs, Mert et al. in 2015 have investigated that the locally transplanted MSCs could suppress the level of IL- 6 and (IL) $-1 \beta$ and enhance IL-10 this effects of MSCs on these cytokines results in decreasing the inflammation (19). In addition above studies, $\mathrm{Gu}$ et al. in 2014 showed that the expression levels of TNF- $\alpha$, IL-1 $\beta$ mRNA and P-I $\kappa$ B- $\alpha$, P-IKK $\beta$, p53 protein were significantly decreased and $\mathrm{I} \kappa \mathrm{B}-\alpha, \mathrm{Bcl}-2$ protein expression levels were significantly increased after brain stroke and mesenchymal stem cell transplantation (20). Calio et al. in 2014 showed that the MSCs are capable of reducing apoptosis and stress oxidative effects by 
enhancing $\mathrm{Bcl} 2$ gene expression and decreasing the by-products of lipid peroxidation in MSCs treated group (21). Mead et al. in 2014 designed a study which demonstrated the bone marrow Mesenchymal stem cells and dental pulp Mesenchymal stem cells are able to produce some neurotrophic cytokines such as BDNF, GDNF, VEGF, PDGF, etc (22). All of the studies above, one of the important effects of MSC s on brain stroke is modulating inflammation and decreasing the apoptosis, so it might be one of the characters of MSCs which help recovering after brain stroke.

As our result shows the administration of MSCs probably reduce the Caspase 3 activity and as a matter of fact the apoptosis and the transplantation the MSCs in combination with Neural Stem cells the outcome is better which could be due to the neuroprotection, anti-oxidant, anti-inflammatory and secreting the neurotrophic cytokines effects of MSCs that lead to making the microenvironment more appropriate for transplanted neural stem cells regeneration activity.

Reducing inflammation after brain stroke by MSCs could lead to neural differentiation of the neural stem cells and in a result it may cause more help neural stem cell to make more regeneration (23). Tang et al. in 2014 designed a study that shows that neural stem cells could promote angiogenesis by secreting VEGF and neurogenesis after brain ischemia (24). Kim et al. in 2014 illustrated that neural stem cells are capable to protect the cells against apoptosis via decreasing the level of Caspase 3 and increasing the $\operatorname{Bcl} 2(14,25)$. Like our result shows the group which received only neural stem cells for brain stroke treatment had significant difference with the sham-operated group. In addition to the neural stem cells ability mentioned above, they might be able to suppress the adverse glial activation in the brain after stroke; it could make neurogenesis faster and more possible (26). Similar to MSCs, the neural stem cells could diminish the inflammation in infracted area by repressing COX-2 (27).

According the mentioned points about the Mesenchymal stem cells and neural stem cells, both of these cells have some ability to improve the neurological function and reduce the brain lesion after brain stroke. In this study we showed that the combination cell therapy is more efficient in recovering after brain stroke and each stem cell type (Mesenchymal stem cells or neural stem cells) could have synergic effects on the other and they could support each other in making more benefits for cell therapy for example the combination cell therapy may have the least Caspase 3 activity and brain lesion volume. So that, although both neural stem cells and Mesenchymal stem cells trans- plantation for brain stroke might be beneficial, the combination cell therapy may provide better neurological outcome.

\section{Acknowledgments}

The authors wish to thank our beloved professor: Dr.T.Talaei-khozani, Dr.MR.Namavar, Dr.H.Azari and Dr.Monabbati to support us in all aspects of learning research.

\section{Potential conflict of interest}

The authors have no conflicting financial interest.

\section{References}

1. Murray CJ, Lopez AD. Mortality by cause for eight regions of the world: Global Burden of Disease Study. Lancet 1997; 349:1269-1276

2. Donnan GA, Fisher M, Macleod M, Davis SM. Stroke. Lancet 2008;371:1612-1623

3. Murray CJ, Lopez AD. Global mortality, disability, and the contribution of risk factors: Global Burden of Disease Study. Lancet 1997;349:1436-1442

4. Barber PA, Auer RN, Buchan AM, Sutherland GR. Understanding and managing ischemic stroke. Can J Physiol Pharmacol 2001;79:283-296

5. Dirnagl U, Iadecola C, Moskowitz MA. Pathobiology of ischaemic stroke: an integrated view. Trends Neurosci 1999; 22:391-397

6. Lo EH, Dalkara T, Moskowitz MA. Mechanisms, challenges and opportunities in stroke. Nat Rev Neurosci 2003; 4:399-415

7. Lakhan SE, Kirchgessner A, Hofer M. Inflammatory mechanisms in ischemic stroke: therapeutic approaches. J Transl Med 2009;7:97

8. Dirnagl U, Iadecola C, Moskowitz MA. Pathobiology of ischaemic stroke: an integrated view. Trends Neurosci 1999; 22:391-397

9. Dharmasaroja P. Bone marrow-derived mesenchymal stem cells for the treatment of ischemic stroke. Journal of Clinical Neuroscience 2009;16:12-20

10. Chung TN, Kim JH, Choi BY, Chung SP, Kwon SW, Suh SW. Adipose-derived mesenchymal stem cells reduce neuronal death after transient global cerebral ischemia through prevention of blood-brain barrier disruption and endothelial damage. Stem Cells Transl Med 2015;4:178-185

11. Paradisi M Alviano F, Pirondi S, Lanzoni G, Fernandez M, Lizzo G, Giardino L, Giuliani A, Costa R, Marchionni C, Bonsi L, Calza L. Human mesenchymal stem cells produce bioactive neurotrophic factors: source, individual variability and differentiation issues. Int J Immunopathol Pharmacol 2014;27:391-402

12. Liu J, Wang Y, Wu Y, Ni B, Liang Z. Sodium butyrate promotes the differentiation of rat bone marrow mesen- 
chymal stem cells to smooth muscle cells through histone acetylation. PLoS One 2014;9:e116183

13. Hosseini SM, Talaei-Khozani T, Sani M, Owrangi B. Differentiation of human breast-milk stem cells to neural stem cells and neurons. Neurol Res Int 2014;2014:807896

14. Wang L, Jiang F, Li Q, He X, Ma J. Mild hypothermia combined with neural stem cell transplantation for hypoxic-ischemic encephalopathy: neuroprotective effects of combined therapy. Neural Regen Res 2014;9:1745-1752

15. Koizumi J, Yoshida Y, Nakazawa T, Ooneda G. Experimental studies of ischemic brain edema: 1. A new experimental model of cerebral embolism in rats in which recirculation can be introduced in the ischemic area. Jpn J Stroke 1986;8:1-8

16. Longa EZ, Weinstein PR, Carlson S, Cummins R. Reversible middle cerebral artery occlusion without craniectomy in rats. Stroke 1989;20:84-91

17. Nasir GA, Mohsin S, Khan M, Shams S, Ali G, Khan SN, Riazuddin S. Mesenchymal stem cells and Interleukin-6 attenuate liver fibrosis in mice. J Transl Med 2013;11:78

18. Cheng Q, Zhang Z, Zhang S, Yang H, Zhang X, Pan J, Weng L, Sha D, Zhu M, Hu X, Xu Y. Human umbilical cord mesenchymal stem cells protect against ischemic brain injury in mouse by regulating peripheral immunoinflammation. Brain Res 2015;1594:293-304

19. Mert T, Kurt AH, Arslan M, Çelik A, Tugtag B, Akkurt A. Anti-inflammatory and Anti-nociceptive Actions of Systemically or Locally Treated Adipose-Derived Mesenchymal Stem Cells in Experimental Inflammatory Model. Inflammation 2015 [Epub ahead of print]

20. Gu N, Rao C, Tian Y, Di Z, Liu Z, Chang M, Lei H. Anti-inflammatory and antiapoptotic effects of mesenchymal stem cells transplantation in rat brain with cerebral ischemia. J Stroke Cerebrovasc Dis 2014;23:2598-2606

21. Calió ML, Marinho DS, Ko GM, Ribeiro RR, Carbonel AF, Oyama LM, Ormanji M, Guirao TP, Calió PL, Reis LA, Simões Mde J, Lisbôa-Nascimento T, Ferreira AT, Bertoncini CR. Transplantation of bone marrow mesenchymal stem cells decreases oxidative stress, apoptosis, and hippocampal damage in brain of a spontaneous stroke model. Free Radic Biol Med 2014;70:141-154

22. Mead B, Logan A, Berry M, Leadbeater W, Scheven BA. Paracrine-mediated neuroprotection and neuritogenesis of axotomised retinal ganglion cells by human dental pulp stem cells: comparison with human bone marrow and adipose-derived mesenchymal stem cells. PLoS One 2014;9: e109305

23. Song J, Cho KJ, Cheon SY, Kim SH, Park KA, Lee WT, Lee JE. Apoptosis signal-regulating kinase 1 (ASK1) is linked to neural stem cell differentiation after ischemic brain injury. Exp Mol Med 2013;45:e69

24. Tang Y, Wang J, Lin X, Wang L, Shao B, Jin K, Wang Y, Yang GY. Neural stem cell protects aged rat brain from ischemia-reperfusion injury through neurogenesis and angiogenesis. J Cereb Blood Flow Metab 2014;34:1138-1147

25. Kim JH, Lee J. Induced neural stem cells protect neuronal cells against apoptosis. Med Sci Monit 2014;20:2759-2766

26. Kim HS, Choi SM, Yang W, Kim DS, Lee DR, Cho SR, Kim DW. PSA-NCAM(+) neural precursor cells from human embryonic stem cells promote neural tissue integrity and behavioral performance in a rat stroke model. Stem Cell Rev 2014;10:761-771

27. Kim JH, Sun W, Han DW, Moon HJ, Lee J. iNSC suppress macrophage-induced inflammation by repressing COX-2. In Vitro Cell Dev Biol Anim 2015;51:157-164 